
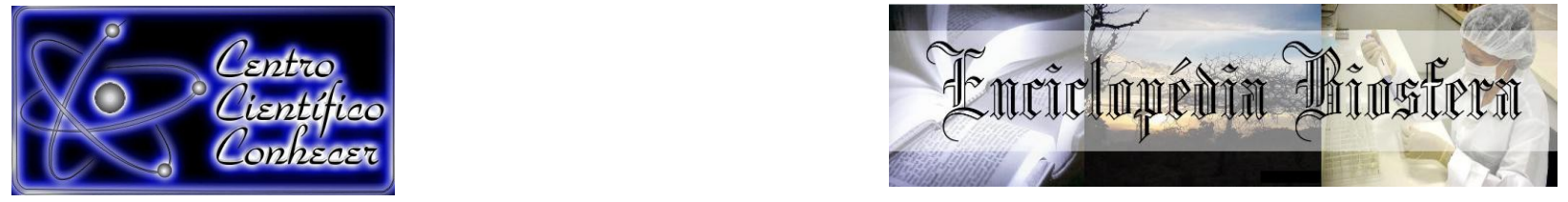

\title{
AVALIAÇÃO DA REGENERAÇÃO NATURAL DE CERRADO EM DIFERENTES CONDIÇÕES DE PERTURBAÇÃO EM JATAÍ-GO
}

Isabel Cristina Silva Souza ${ }^{1}$, Gilson Pereira da Silva ${ }^{1}$, Wendy Carniello Ferreira ${ }^{2}$, Frederico Augusto Guimarães Guilherme ${ }^{3}$

1 Aluno do curso de graduação em Engenharia Florestal. Universidade Federal de Goiás - Regional Jataí, Jataí, Goiás, Brasil.

2 Prof. do curso de Engenharia Florestal. Universidade Federal de Goiás - Regional Jataí, Jataí, Goiás, Brasil. e-mail: wcferreira_4@hotmail.com 3 Prof. do curso de Ciências Biológicas. Universidade Federal de

Goiás - Regional Jataí, Jataí, Goiás, Brasil.

Recebido em: 06/04/2018 - Aprovado em: 10/06/2018 - Publicado em: 20/06/2018 DOI: 10.18677/EnciBio_2018A15

\begin{abstract}
RESUMO
Este estudo teve como objetivo avaliar a regeneração natural em três áreas de cerradão sob diferentes tipos de interferência, em Jataí - GO. Foram alocadas 30 parcelas de $5 \times 5$ metros, sendo 10 em cada área. Estas áreas foram denominadas como preservada, pastoreio e queimada. Foram levantados todos os indivíduos com DAP $\leq 5 \mathrm{~cm}$ e altura $\geq 30 \mathrm{~cm}$. As espécies foram classificadas quanto a composição florística e a diversidade da regeneração natural foi estimada pelo índice de diversidade de Shannon e pelo índice de equabilidade de Pielou. Para avaliar as possíveis diferenças entre as médias das variáveis: densidade, diâmetro médio à altura do solo, altura média e riqueza nas áreas em diferentes condições avaliadas (preservada, queimada e pastoreio), aplicou-se o Teste $t(p<0,05)$. Nas áreas que sofreram interferência (pastoreio e queimada), as plantas em regeneração natural tiveram menor desenvolvimento em altura e diâmetro em relação a área preservada. A interferência do gado nos fragmentos de cerradão estudados é mais impactante.
\end{abstract}

PALAVRAS-CHAVE: cerradão, conservação, impacto ambiental.

\section{EVALUATION OF NATURAL REGENERATION OF CERRADO IN DIFFERENT CONDITIONS OF DISTURBANCE IN JATAÍ-GO}

\begin{abstract}
The objective of this study was to evaluate the natural regeneration in three areas of forested savanna under different types of interference, in Jataí - GO. 30 plots of $5 \times 5$ meters were allocated, of which 10 in each area. These areas were designated as preserved, grazing and burned. All individuals with $\mathrm{DBH} \leq 5 \mathrm{~cm}$ and height $\geq 30 \mathrm{~cm}$ were evaluated. The species were classified as floristic composition and the diversity of natural regeneration was estimated by the Shannon diversity index and the Pielou equability index. The t-test $(p<0.05)$ was applied to evaluate the possible differences between the means of the variables density, mean diameter at ground level, average height and richness in the areas under different conditions (preserved, burned and grazing). In the areas that underwent interference (grazing and burning), the plants in
\end{abstract}


natural regeneration had lower development in height and diameter in relation to the preserved area. The interference of the cattle in the fragments studied is more impactant.

KEYWORDS: forested savanna, conservation, environmental impact

\section{INTRODUÇÃO}

O Cerrado é o segundo maior bioma da América do Sul, ocupando uma área de $2.036 .448 \mathrm{~km}^{2}$, cerca de $22 \%$ do território nacional (CÂNDIDO et al., 2016). As transformações de uso da terra neste bioma têm levado a modificações profundas na estrutura e funcionamento de seus ecossistemas. Estimativas indicam que restam menos de $17 \%$ de áreas de cerrado não antropizadas. A pecuária é a principal atividade econômica responsável pela conversão da vegetação natural deste bioma, seguida pela agricultura e pela demanda por carvão vegetal para a indústria siderúrgica (BRASIL, 2014; PEREIRA et al., 2014.). Além da biodiversidade, as mudanças do uso da terra no cerrado comprometem o meio físico, em particular os recursos hídricos na região (LIMA et al., 2016).

No Cerrado a evidencia dos impactos ambientais são as grandes áreas homogêneas com pastagens e agricultura, com a presença de fragmentos florestais muito fragmentados e esparsos. Quando as áreas são abandonadas devido à baixa produtividade, inicia-se o processo de regeneração natural, com influência dos fatores ambientais (SANTOS et al., 2017). A regeneração por brotação tem maior êxito no processo de recuperação da cobertura vegetal do cerrado. Essa capacidade peculiar das espécies do cerrado de recobrir o terreno a partir da rebrota de estruturas subterrâneas depende das propriedades físicas e químicas do solo e do tempo decorrido após o desmatamento (PAULO et al., 2015).

Muito se discute sobre o efeito do fogo ao ecossistema, podendo ser positivo ou desprezível para o desenvolvimento ou ainda degradante do meio. Contudo, o efeito e intensidade de alteração no ambiente terá influência de acordo com as características do ecossistema que atinge (COSTA; RODRIGUES, 2015). Já com relação as práticas de pastoreio de animais domésticos, vários autores confirmam o efeito deletério das mesmas, sendo fator que ameaça a manutenção e conservação das fitofisionomias de Cerrado (OLIVEIRA, 2014; FERREIRA et al., 2015; SILVA et al., 2015; MARMONTEL; RODRIGUES, 2015; FERREIRA et al., 2016; SILVA et al., 2017). O pastoreio só apresenta efeitos benéficos sobre a vegetação nativa quando utilizado para controle de gramíneas exóticas presentes no sub-bosque (MESQUITA et al., 2015; FRAGOSO et al., 2017).

De acordo com Cava et al. (2016), a definição de qual técnica adotar para a recuperação da vegetação do Cerrado é um desafio, especialmente pela escassez de estudos científicos que fundamentem a aplicação de cada técnica em diferentes contextos. Em situações nas quais a resiliência do ecossistema é elevada, a regeneração natural pode ser tão eficaz para recuperação do sistema quanto técnicas de restauração ativa. Portanto, estudos que avaliem a regeneração natural de fitofisionomias de Cerrado são fundamentais para recuperação e conservação deste importante Bioma. Desta forma, o objetivo deste estudo foi avaliar a regeneração natural em fragmentos de cerradão, analisando seu comportamento em três áreas sob diferentes tipos de interferência. Tendo como hipótese que áreas preservadas tenham maior riqueza, crescimento em altura e diâmetro e, densidade de indivíduos do que áreas antropizadas (pastoreio e queimada). 


\section{MATERIAL E MÉTODOS}

O presente estudo foi conduzido em fragmentos de cerradão localizados no Câmpus Jatobá da Universidade Federal de Goiás - Regional Jataí, no município de Jataí, GO, a oito quilômetros do centro da cidade. O clima da região é do tipo Aw considerado tropical Mesotérmico, segundo a classificação de KOPPEN, com duas estações climáticas bem definidas pelo regime sazonal de chuvas e verões quentes, com precipitações de maior índice pluviométrico entre outubro a abril e tendo um período de estiagem entre maio a setembro. A temperatura média anual é de $23,7^{\circ} \mathrm{C}$ e a precipitação anual média de $1629,3 \mathrm{~mm}$, com chuva no verão e seca no inverno (INMET, 2017).

O tipo de solo predominante na área é o Latossolo Vermelho-Escuro distroférrico (LRd), apresentando textura muito argilosa e argilosa, oriundos do basalto da formação Serra Geral, sendo profundos, muito porosos e permeáveis, com baixa suscetibilidade à erosão (SCOPEL; SILVA, 2001). A vegetação primitiva da região onde estão localizados os fragmentos estudados pode ser considerada como transição entre floresta estacional e cerradão, se apresentando, atualmente, amplamente fragmentada e em diversos estádios de sucessão (OLIVEIRA et al., 2015).

Para realizar o levantamento da regeneração natural, foram selecionadas três áreas de cerradão em diferentes condições de perturbação. A primeira, denominada preservada, apresenta antropização menos intensa que as outras duas áreas. A segunda, denominada área queimada. Esta área sofreu o último incêndio no ano de 2015, na estação de seca, apresentando grande quantidade de capim nas bordas e no interior da mesma. Na terceira, denominada área de pastoreio, verificou-se presença de gado em altas lotações, consumindo e pisoteando a regeneração natural.

Foram alocadas, aleatoriamente, 10 parcelas em cada tratamento (preservada, queimada e pastoreio), de $5 \times 5 \mathrm{~m}$, isto é, $25 \mathrm{~m}^{2}$ cada, totalizando uma área amostral de $750 \mathrm{~m}^{2}$. No interior das parcelas, foram incluídos todos os indivíduos com DAS (diâmetro a $1,3 \mathrm{~m}$ de altura do solo) $\leq 5 \mathrm{~cm}$ e altura $\geq 30 \mathrm{~cm}$, segundo o protocolo de parcelas permanentes dos Biomas Cerrado e Pantanal (FELFILI et al., 2005). Foram medidos, em todos esses indivíduos: o DAS (diâmetro em nível do solo) e a altura total. Para medição do DAS, utilizou-se o paquímetro digital modelo Zaas precision $0-200 \mathrm{~mm}$ e, para medir a altura, utilizou-se a fita métrica. Para as espécies não identificadas no local, realizou-se a coleta do material botânico para posterior identificação no Herbário Jatainese Prof. Germano Guarim Neto da Universidade Federal de Goiás, Regional Jataí.

Os parâmetros fitossociológicos estimados foram os seguintes: riqueza de espécies; densidade, dominância e frequência em seus valores absolutos e relativos; valor de importância; índice de diversidade de Shannon ( $\left.\mathrm{H}^{\prime}\right)$ e índice de equabilidade de Pielou (J').

Para avaliar as possíveis diferenças entre as médias das variáveis: densidade, diâmetro médio à altura do solo, altura média e riqueza nas áreas em diferentes condições avaliadas (preservada, queimada e pastoreio), aplicou-se o Teste $\mathrm{t}$, considerando o nível de significância de $5 \%(p<0,05)$. As análises estatísticas foram realizadas com auxílio do software SPSS $20.0{ }^{\circledR}$ for Windows (IMB SPSS, Armonk, New York, USA). 


\section{Composição florística}

\section{RESULTADOS E DISCUSSÃO}

A Tabela 1 apresenta a composição florística da regeneração natural das três áreas avaliadas. Nas parcelas amostradas, foram registrados 407 indivíduos pertencentes a 65 espécies arbóreas, representadas por 28 famílias.

TABELA 1 - Lista de espécies arbóreas da regeneração natural encontradas em três áreas de cerradão sob diferentes tipos de interferência no município de Jataí-GO.

\begin{tabular}{|c|c|c|c|c|}
\hline \multirow{2}{*}{ Espécies } & \multicolumn{3}{|c|}{ Áreas } & \multirow{2}{*}{ - Total } \\
\hline & Pastoreio & Preservada & Queimada & \\
\hline Alibertia sessilis (Vell.) K.Schum. & 1 & 11 & & 12 \\
\hline Andira sp. & 4 & 1 & & 5 \\
\hline Astronium fraxinifolium Schott & & & 1 & 1 \\
\hline Bauhinia sp. 1 & & 11 & 1 & 12 \\
\hline Bauhinia sp. 2 & & 2 & 2 & 4 \\
\hline Brosimum gaudichaudii Tréc. & & 2 & 4 & 6 \\
\hline Byrsonima sericea DC. & 2 & 7 & 7 & 16 \\
\hline Casearia sp. 1 & & 1 & & 1 \\
\hline Casearia sp. 2 & & & 1 & 1 \\
\hline Casearia sylvestris Sw. & & 1 & 7 & 8 \\
\hline Chrysophyllum marginatum (Hook. \& Arn.) Radlk. & 14 & 9 & 12 & 35 \\
\hline Coccoloba mollis Casaretto & 3 & & & 3 \\
\hline Connarus suberosus Planch. & & 1 & 1 & 2 \\
\hline Copaifera langsdorffii Desf. & 15 & & & 15 \\
\hline Coussarea hydrangeifolia (Benth.) Müll.Arg. & & 2 & & 2 \\
\hline Cupania vernalis Cambess. & 1 & & 5 & 6 \\
\hline Curatella americana L. & 1 & & & 1 \\
\hline Cyclolobium brasiliense & 1 & & & 1 \\
\hline Davilla elliptica St.-Hil. & & 2 & 1 & 3 \\
\hline Dimorphandra mollis Benth. & & 2 & 1 & 3 \\
\hline Dipteryx alata Vogel. & & & 1 & 1 \\
\hline Emmotum nitens (Benth.) Miers & & 1 & & 1 \\
\hline Erythroxylum deciduum A.St.-Hil. & 10 & 28 & 31 & 69 \\
\hline Euphorbiaceae 1 & 1 & & & 1 \\
\hline Fabaceae 1 & 1 & & & 1 \\
\hline Handroanthus ochraceus (Cham.) Mattos. & & & 3 & 3 \\
\hline Indeterminada 1 & 1 & & & 1 \\
\hline Indeterminada 10 & & & 1 & 1 \\
\hline Indeterminada 11 & & & 1 & 1 \\
\hline Indeterminada 12 & & & 1 & 1 \\
\hline Indeterminada 2 & 1 & & & 1 \\
\hline Indeterminada 3 & 1 & & & 1 \\
\hline Indeterminada 4 & & 3 & & 3 \\
\hline Indeterminada 5 & & 1 & & 1 \\
\hline Indeterminada 6 & & 1 & & 1 \\
\hline Indeterminada 7 & & 1 & & 1 \\
\hline Indeterminada 8 & & 1 & & 1 \\
\hline Indeterminada 9 & & 1 & & 1 \\
\hline Jacaranda brasiliana (Lam.) Pers. & 1 & & 2 & 3 \\
\hline Luehea paniculata Mart. & 7 & 5 & 3 & 15 \\
\hline Machaerium acutifolium Vogel. & 1 & & & 1 \\
\hline Matayba guianensis Aubl. & 1 & & 25 & 26 \\
\hline Myracrodruon urundeuva Allemão & 1 & 7 & 1 & 9 \\
\hline Myrcia sp. & 3 & 4 & & 7 \\
\hline Myrcia tomentosa (Aubl.) DC. & & 7 & 3 & 10 \\
\hline Myrsine umbellata Mart. & & & 1 & 1 \\
\hline Nectandra cissiflora Nees. & & & 1 & 1 \\
\hline NCICLOPÉDIA BIOSFERA, Centro Científico Co & & & & 018 \\
\hline
\end{tabular}


Nectandra sp.

Persea sp.

Protium heptaphyllum (Aubl.) Marchand.

Pseudobombax tomentosum (Mart.) A.Robyns

Qualea multiflora Mart.

Rhamnidium elaeocarpum Reissek

Roupala montana Aubl.

Sapium haematospermum Müll.Arg.

Senegalia polyphylla (DC.) Britton \& Rose.

Solanaceae 1

Solanaceae 2

Styrax ferrugineus Nees \& Mart.

Tapirira guianensis Aubl.

Terminalia argentea Mart.

Tocoyena formosa (Cham. \& Schltdl.) K.Schum. Xylopia aromatica (Lam.) Mart.

Total

\begin{tabular}{cccc} 
& 1 & & 1 \\
& & 1 & 1 \\
& 1 & & 1 \\
& 1 & & 1 \\
1 & & 1 \\
1 & 1 & 8 \\
& 1 & 3 & 4 \\
& & 2 & 2 \\
& 1 & 51 & 52 \\
& & & 1 \\
& & 1 & 1 \\
& & 5 & 5 \\
& 1 & 2 & 3 \\
& 6 & 5 & 11 \\
& 3 & 2 & 14 \\
& & 1 & 1 \\
\hline $\mathbf{8}$ & $\mathbf{1 2 9}$ & $\mathbf{1 9 1}$ & $\mathbf{4 0 7}$ \\
\hline
\end{tabular}

Analisando as áreas de pastoreio, preservada e queimada, observou-se que a área de queimada apresentou maior número de indivíduos (191) e de espécies (36), sendo que na área de pastoreio ocorreu o inverso, o menor número de indivíduos (87) e menor número de espécies (24).

Em áreas onde ocorrem queimadas com maior frequência, ocorrem em menor intensidade devido a menor quantidade de material combustível. Com isso, essa variação até pode levar a um aumento da riqueza de espécies e da diversidade diminuindo a intensidade do fogo e aumentando a frequência (ARAUJO et al. 2016; SANTOS et al. 2017). Em ambientes com alta severidade de queimadas, a regeneração após fogo envolve processos mais longos de recuperação com um menor número de indivíduos regenerantes (CROTTEAU et al. 2013).

Áreas pastejadas referem-se à pastagens naturais, semi-naturais, ou outras áreas naturais utilizadas para pastejo. Mudanças na heterogeneidade espacial devido ao pastejo implicam em alterações na diversidade do habitat, como alterações na diversidade florística, que atua nos padrões de competição entre espécies vegetais. Transformações podem ocorrer na diversidade da comunidade de consumidores, a qual abrange desde invertebrados, até mamíferos (WALLIS DE VRIES et al., 2007). O pisoteio é o dano provocado pelo impacto direto dos cascos do animal sobre a planta e o solo (PAULO; ALMEIDA, 2016). Isso pode ser uma das razões do menor número de indivíduos e de espécies na área. O pisoteio pelo gado reduz a cobertura vegetal, por ser capaz de matar plantas muito jovens ou danificar o dossel de plantas adultas, compactar ou desestabilizar a superfície do solo, redistribuir a camada de serrapilheira e aumentar as áreas de solo descoberto (DIAS FILHO, 2005).

Notou-se que algumas espécies existem somente em determinadas áreas como Handroanthus ocharaceus, Persea sp. e Xylopia aromatica, que ocorrem na área de queimada. Já espécies como Cyclolobium brasiliense, Copaifera langsdorffi e Curatella americana ocorrem em área de pastejo. As espécies como Protium heptaphyllum, Pseudobombax tomentosum, Coussarea hydrangeifolia, Qualea multiflora e Emmotum nitens estavam presentes na área preservada.

Em ambas as áreas de pastoreio e de queimada, a família Fabaceae ocorreu em com maior representatividade. As espécies responsáveis por essa maior representatividade foram: Senegalia polyphylla e Copaifera langsdorffii. A espécie Senegalia polyphylla é considerada semidecídua e heliófita, característica dos estágios iniciais da sucessão. Produz anualmente grandes quantidades de sementes 
que garantem a regeneração natural (SCABORA et al. 2011). Em função da rusticidade e crescimento rápido, é muito indicada para recuperação de áreas degradadas (COELHO et al., 2016). A espécie Copaifera langsdorffii é caracterizada como indiferente, isto é, varia desde terrenos secos (cerrado sentido restrito) a inundados periodicamente ou alagados pelos cursos d'água (matas de galeria ou matas ciliares) (PASA et al. 2012).

Erythroxylum deciduum teve representatividade nas três áreas, nas áreas de pastoreio e queimada foi a terceira espécie com maior número de indivíduos $e$, na área preservada, foi a primeira espécie em destaque. A família a qual esta espécie pertence, Erythroxylaceae, é uma das famílias mais representativas do bioma cerrado, tem seus principais centros de diversidade e endemismo na América do Sul, no sudeste asiático e em Madagascar (LOIOLA et al., 2007). Esse gênero é bastante distribuído nas regiões tropicais e subtropicais do mundo. Portanto, é considerado um dos gêneros mais comuns da vegetação do cerrado brasileiro (SOUZA; LORENZI, 2012).

\section{Diversidade da regeneração natural}

Os valores dos índices utilizados para estimar a diversidade das três áreas avaliadas (índice de Shannon e a equalibidade de Pielou) podem ser observados na Tabela 2. Notou-se que a área preservada apresentou um valor maior de H' do que as áreas que sofreram alguma interferência. Quanto maior o valor de H', maior é a diversidade florística. O J' representa a uniformidade da distribuição dos indivíduos entre as espécies existentes na área de estudo. Verificou-se que o J' da área de pastoreio e preservada possui o mesmo valor, mostrando que as espécies estão melhor distribuídas na área do que na área queimada, onde existe um valor menor.

TABELA 2 - Índices de diversidade e equabilidade estimados para a regeneração natural em três áreas de cerradão sob diferentes tipos de interferência no município de Jataí-GO. H': Índice de Shannon Índice e J': Índice de Pielou.

\begin{tabular}{lll}
\hline Áreas & H' $^{\prime}$ & J' \\
\hline Pastoreio & 2,65 & 0,83 \\
Preservada & 2,96 & 0,83 \\
Queimada & 2,66 & 0,74 \\
\hline
\end{tabular}

Analisando o valor obtido na área preservada e comparando com trabalhos semelhantes, notou-se que o $\mathrm{H}^{\prime}$ encontrado $(2,96)$ para as áreas: queimada e preservada foi maior do que o valor obtido nos trabalhos de Ferreira et al. (2013), em uma área próxima (Transição de mata ciliar/cerradão degradado), obtendo valor de diversidade $(2,62)$ e Vale et al. (2009), em cerradão, com H'= 2,26.

Já os valores de J' variam de 0 a 1 . Valores próximos a zero indicam que há dominância ecológica mais pronunciada de algumas espécies no ambiente. $O$ valor obtido na área preservada foi de 0,83 , foi superior a ambos trabalhos de Pereira et al. (2014), para uma área de transição entre cerrado típico e cerradão $(0,913)$ e Vale et al. (2009) $\left(\mathrm{J}^{\prime}=0,59\right)$. Notou-se assim, que a área preservada tem uma adequada distribuição dos seus indivíduos. 
Analisando o valor obtido na área queimada e comparando com trabalhos semelhantes, notou-se que o H' encontrado $(2,66)$, foi um valor menor comparado com outros trabalhos de regeneração, como Aquino et al. (2014) os quais caracterizaram uma área de cerrado sentido restrito, obtendo valor de diversidade de 3,39 .

O valor de J' obtido na área queimada foi de 0,74 , maior do que o obtido no trabalho de Vale et al. (2009), estudando a regeneração natural de cerradão antropizado em Uberlândia, MG $(0,59)$ e com valor superior a esses trabalhos, Santos et al. (2017), estudando uma área de savana antropizada, também em Minas Gerais $(0,83)$.

Analisando o valor obtido na área de pastoreio e comparando com trabalhos em áreas antropizadas pelo mesmo fator, notou-se que o $H^{\prime}$ encontrado $(2,65)$ foi um valor inferior ao obtido por Ferreira et al. (2011), cujo H' foi de 2,88. De maneira geral, para esse estudo, os índices de diversidade apresentaram valores baixos quando comparados com trabalhos semelhantes, devido às áreas apresentarem alterações antrópicas.

\section{Comparações entre as áreas em diferentes condições de perturbação}

As Tabelas 3, 4 e 5 apresentam as comparações das áreas entre si, realizadas por meio do Teste t, em nível de significância de $5 \%$, com as variáveis: densidade (plantas/ha); riqueza, diâmetro a altura do solo (DAS) e altura.

Observa-se, na Tabela 3, comparando-se as áreas queimada e preservada, que houveram diferenças significativas para DAS, em que a área preservada apresenta maior desenvolvimento do DAS, do que a área de queimada. Sabe-se que a presença do fogo é considerada um fator estruturador da vegetação nas savanas (COUTINHO, 1990). Portanto, este resultado foi observado devido ao fato do fogo poder alterar a estrutura, a composição florística e o crescimento das plantas, ocasionando limitação no recrutamento de novas espécies (COSTA; RODRIGUES, 2015).

TABELA 3 - Comparação das variáveis, densidade (plantas/ha); riqueza, diâmetro a altura do solo $(\mathrm{mm})$ e altura $(\mathrm{cm})$ entre as áreas de Queimada e Preservada no município de Jataí-GO.

\begin{tabular}{lcc}
\hline Variáveis & Área & Média \\
\hline \multirow{2}{*}{ Densidade } & Queimada & $7640,00 \mathrm{a}$ \\
& Preservada & $5160,00 \mathrm{a}$ \\
\hline \multirow{2}{*}{ Riqueza (plantas/ha) } & Queimada & $7,40 \mathrm{a}$ \\
& Preservada & $6,80 \mathrm{a}$ \\
\hline \multirow{2}{*}{ DAS $(\mathrm{mm})$} & Queimada & $11,93 \mathrm{a}$ \\
& Preservada & $16,52 \mathrm{~b}$ \\
\hline \multirow{2}{*}{ Altura $(\mathrm{cm})$} & Queimada & $117,76 \mathrm{a}$ \\
& Preservada & $109,84 \mathrm{a}$ \\
\hline
\end{tabular}

*Médias seguidas de mesmas letras não diferem estatisticamente entre si. 
Notou-se que a área de pastoreio (Tabela 4) apresentou, significativamente, menores médias para densidade (plantas/ha) e altura da regeneração, em relação à área queimada. De acordo com Santos et al. (2017), fogo e pastejo removem área foliar das plantas. No entanto, o pastejo continua a reduzir o material verde de lâminas foliares ao longo de toda a estação de crescimento, afetando a taxa de acumulação e a altura das plantas, devido a predação do gado. O pastoreio ocasiona redução da diversidade de plantas herbáceas e arbustos, em que a ação do pastejo é seletiva, isto é, está ligado com a apetência das plantas ao paladar dos herbívoros domésticos (DIAS-FILHO, 2005).

TABELA 4 - Comparação das variáveis, densidade (plantas/ha); riqueza, diâmetro a altura do solo $(\mathrm{mm})$ e altura $(\mathrm{cm})$ entre as áreas de Queimada e Pastoreio no município de Jataí-GO.

\begin{tabular}{lcc}
\hline Variáveis & Área & Média \\
\hline \multirow{2}{*}{ Densidade } & Queimada & $7640,00 \mathrm{a}$ \\
& Pastoreio & $3480,00 \mathrm{~b}$ \\
\hline \multirow{2}{*}{ Riqueza (plantas/(ha) } & Queimada & $7,40 \mathrm{a}$ \\
\multirow{2}{*}{ DAS $(\mathrm{mm})$} & Pastoreio & $4,70 \mathrm{a}$ \\
\hline \multirow{2}{*}{ Altura $(\mathrm{cm})$} & Queimada & $11,93 \mathrm{a}$ \\
& Pastoreio & $12,43 \mathrm{a}$ \\
\hline
\end{tabular}

*Médias seguidas de mesmas letras não diferem estatisticamente entre si.

Quando foram comparadas as áreas de pastoreio e queimada (Tabela 5), houveram diferenças significativas para DAS e para Altura. A área queimada apresentou plantas de maior porte, em comparação com a de pastoreio, mostrando assim que a presença de animais interfere no desenvolvimento das espécies regenerantes, pelo pisoteio e herbivoria. Nestas situações, a intensidade de pastejo também pode culminar em distúrbios erosivos do solo e a redução do pool de espécies vegetais para apenas algumas espécies tolerantes ao pastejo, diminuindo, portanto, a diversidade florística (DIAS-FILHO, 2005).

TABELA 5 - Comparação das variáveis, densidade (plantas/ha); riqueza, diâmetro a altura do solo $(\mathrm{mm})$ e altura $(\mathrm{cm})$ entre as áreas de Preservada e Pastoreio no município de Jataí-GO.

\begin{tabular}{lcc}
\hline Variáveis & Área & Média \\
\hline \multirow{2}{*}{ Densidade } & Preservada & $5160,00 \mathrm{a}$ \\
& Pastoreio & $3480,00 \mathrm{a}$ \\
\hline \multirow{2}{*}{ Riqueza (plantas/ha) } & Preservada & $6,80 \mathrm{a}$ \\
\multirow{2}{*}{ DAS $(\mathrm{mm})$} & Pastoreio & $4,70 \mathrm{a}$ \\
\hline \multirow{2}{*}{ Altura $(\mathrm{cm})$} & Preservada & $16,52 \mathrm{a}$ \\
& Pastoreio & $12,43 \mathrm{~b}$ \\
\hline
\end{tabular}

*Médias seguidas de mesmas letras não diferem estatisticamente entre si. 


\section{CONCLUSÕES}

A diversidade encontrada foi menor em comparação com fitofisionomias semelhantes ao do fragmento, mostrando que as áreas estão alteradas devido às interferências que foram ocasionadas. No entanto, estes fragmentos são importantes na manutenção e preservação dessa biodiversidade local.

Comparando as áreas entre si, observou-se que as áreas que sofreram interferência (pastoreio e queimada), as plantas em regeneração natural tiveram menor desenvolvimento em altura e diâmetro em relação a área preservada. Comparando a área queimada e pastoreio, observou-se menor desenvolvimento da área de pastoreio, indicando que esta última interferência nos fragmentos de cerradão estudados é mais impactante.

\section{AGRADECIMENTOS}

Ao CNPq e à FAPEG, no âmbito do Projeto PELD Jataí - Pesquisas Ecológicas de Longa Duração (Processo No 2012/10267001108); ao CNPq pela bolsa Produtividade em Pesquisa (PQ2) ao FAG Guilherme.

\section{REFERÊNCIAS}

AQUINO, F. G.; PEREIRA, C. S.; PASSOS, B. F; OLIVEIRA, M. C. Composição florística e estrutural de um cerrado sentido restrito na Área de Proteção de Manancial Mestre D'Armas, Distrito Federal. Bioscience Journal, Uberlândia, v. 30, n. 2, p. 565-575, Mar./Abr. 2014. Disponível em: http://www.seer.ufu.br/index.php/biosciencejournal/article/view/18305/13775

ARAÚJO, F. C.; SANTOS, R. M.; COELHO, P. A. O papel do distúrbio na regeneração natural dos ecossistemas florestais. Revista Ciências Agroambientais Alta Floresta. v.14, n.1, p.131-142, 2016. Disponível em: periodicos.unemat.br/index.php/rcaa/article/view/1420/1398

BRASIL. Ministério do Meio Ambiente. Plano de ação para prevenção e controle do desmatamento e das queimadas no Cerrado: $2^{\mathrm{a}}$ fase. Brasília: MMA, 2014. 132p.

CÂNDIDO, J. B.; LIMA, D. P.; TEIXEIRA, P. R.; SOUZA, P. B. Florística do estrato arbustivo-arbóreo de uma área de cerrado sensu stricto, Gurupi, Tocantins. Enciclopédia Biosfera, Centro Científico Conhecer - Goiânia, v.13 n.24; p.17441752. 2016.

Disponível

em: http://www.conhecer.org.br/enciclop/2016b/biologicas/Floristica.pdf. 10.18677/EnciBio_2016B_160.

CAVA, M. G. B.; ISERNHAGEN, I.; MENDONÇA, A. H.; DURIGAN, G. Comparação de técnicas para restauração da vegetação lenhosa de Cerrado em pastagens abandonadas. Hoehnea, São Paulo, v.43, n.2, p.301-315, 2016. Disponível em: $<$ tttp://www.scielo.br/scielo.php?

script=sci_arttext\&pid=S223689062016000200301\&lng=en\&nrm=iso>. Acesso em 16 fev. 2018. DOI: http://dx.doi.org/10.1590/2236-8906-18/2016.

COELHO, G, L, N.; CARVALHO, L. M. T.; GOMIDE, L. R. Modelagem preditiva de distribuição de espécies pioneiras no Estado de Minas Gerais. Pesquisa Agropecuária Brasileira, Brasília, v.51, n.3, p.207-214, 2016. Disponível em: 
$<$ http://www.scielo.br/scielo.php?

script=sci_arttext\&pid=S0100204X2016000300207\&lng=en\&nrm=iso>. Acesso em: 21 fev. 2018. http://dx.doi.org/10.1590/S0100-204X2016000300002.

COSTA, Y. T.; RODRIGUES, S. C. Efeito do fogo sobre vegetação e solo a partir de estudo experimental em ambiente de cerrado. Revista do Departamento de Geografia - USP. São Paulo, 2015. p.149-165. v. 30. Disponível em: http://www.revistas.usp.br/rdg/article/view/101686/107761. http://dx.doi.org/10.11606/rdg.v30i0.101686

COUTINHO, L.M. Fire in the ecology of the Brazilian cerrado. In: GOLDAMMER, J. G. (ed.). Fire in the Tropical Biota. Berlin, Springer-Verlag, 1990. p. 82-105, 1990

CROTTEAU, J. S.; VARNER, J. M.; RITCHIE, M. W. Postfire regeneration across a fire severity gradient in the southern Cascades. Forest Ecology and Management, Amsterdam, v.287, p.103-112, 2013. Disponível em: www.sciencedirect.com/science/article/pii/S0378112712005567 DOI: https://doi.org/10.1016/j.foreco.2012.09.022

DIAS-FILHO, M.B. Degradação de pastagens. Processos, causas e estratégias de recuperação. $2^{\mathrm{a}}$.Ed. 2005. Belém: Embrapa Amazônia Oriental. 173p.

FELFILI, J. M.; CARVALHO, A. R.; HAIDAR, R. F. Manual para o monitoramento de parcelas permanentes nos biomas Cerrado e Pantanal. Brasília, Editora da Universidade de Brasília, Departamento de Engenharia Florestal, 2005. 51 p.

FERREIRA, G. A.; NAVES, R. V.; CHAVES, L. J.; VELOSO, V. R.; SOUZA, E. R. B. Produção de frutos de populações naturais de pequizeiro no estado de Goiás. Revista Brasileira de Fruticultura Jaboticabal, v.37, n.1, p.121-129, 2015. Disponível em <http://www.scielo.br/scielo.php? script=sci_arttext\&pid=S010029452015000100121\&lng=en\&nrm=iso>. Acesso em: 19 fev. 2018. DOI: http://dx.doi.org/10.1590/0100-2945-404/13.

FERREIRA, L. V.; PAROLIN, P.; MATOS, D. C. L.; CUNHA, D. A., CHAVES, P. P. et al. The effect of exotic grass Urochloa decumbens (Stapf) R.D.Webster (Poaceae) in the reduction of species richness and change of floristic composition of natural regeneration in the Floresta Nacional de Carajás, Brazil. Anais da Academia Brasileira de Ciências, Rio de Janeiro, v.88, supl.1, p.589-597, 2016. Disponível em: $\quad<h t t p: / / w w w . s c i e l o . b r / s c i e l o . p h p ?$ script=sci_arttext\&pid=S000137652016000200589\&Ing=en\&nrm=iso>. Acesso em: 21 fev. 2018. DOI: http://dx.doi.org/10.1590/0001-3765201620150121.

FERREIRA, W. C.; OLIVEIRA, P. R; CORREAA, R, S.; SANTOS, R. C.; FREITAS, D. $V$. Análise de um fragmento de cerrado degradado no município de Jataí, GO como base do processo de recuperação. Enciclopédia Biosfera. Centro Científico Conhecer - Goiânia, v.9, n.16; p.132-147. 2013. Disponível em: http://www.conhecer.org.br/enciclop/2013a/agrarias/Analise\%20de\%20um \%20fragmento.pdf 
FERREIRA, W.C.; FERREIRA, M.J.; SANTOS, R. C.; FREITAS, D. V.; COELHO, C. $P$. Avaliação silvicultural de espécies arbóreas nativas regenerantes em um povoamento florestal. Enciclopédia biosfera, Centro Científico Conhecer. v. 7, p. 17 , 2011.

Disponível

em:

http://www.conhecer.org.br/enciclop/2011a/agrarias/avaliacao\%20silvicultural.pdf

FRAGOSO, R. O.; CARPANEZZI, A. A.; KOEHLER, H. S.; ZUFFELLATO-RIBAS, K. C. Barreiras ao estabelecimento da regeneração natural em áreas de pastagens abandonadas. Ciência Florestal, v. 27, n. 4, 2017. Disponível em: periodicos.ufsm.br/cienciaflorestal/article/view/30331/pdf.

$10.5902 / 1980509830331$

INMET. Instituto Nacional de Meteorologia - INMET, 2017 Disponível em http://www.inmet.gov.br. Acesso em: 17/11/2017.

LIMA, P. A. F.; ALBUQUERQUE, L.B.; MALAQUIAS, J. V.; GATTO, A.; AQUINO, F. G. Eficiência de regenerantes como indicador de restauração ecológica no Cerrado, Brasil. Revista de Ciências Agrárias, v. 39, n. 3, p.437-446. 2016. Disponível em: www.researchgate.net/publication/314302927_Eficiencia_de_regenerantes_como_in dicador_de_restauracao_ecologica_no_Cerrado_Brasil. DOI: 10.19084/RCA15106.

LOIOLA, M. I. B.; AGRA, M. F.; BARACHO, G. S.; QUEIROZ, R. T. Flora da Paraíba, Brasil: Erythroxylaceae Kunth. Acta Botanica Brasilica, São Paulo, v. 21, n. 2, p. 473-487, 2007. Disponível em: <http://www.scielo.br/scielo.php? script=sci_arttext\&pid=S0102-33062007000200020\&Ing=en\&nrm=iso>. DOI: http://dx.doi.org/10.1590/S0102-33062007000200020.

MARMONTEL, C, V. F.; RODRIGUES, V. A. Avaliação qualitativa de nascentes com diferentes coberturas do solo e conservação da vegetação em seu entorno no córrego Pimenta. Scientia Agrária Paranaensis, v. 14, n. 1, p. 53-59, 2015. Disponível em: <http://hdl.handle.net/11449/140390>. DOI: http://dx.doi.org/10.1818/sap.v14i1.9540

MESQUITA, C. A. B.; HOLVORCEM, C. G. D.; BRACALE, H.; HENRIQUES, J. J. P.; DIAS, J. D. S. et al. Geração de renda pela restauração florestal em larga escala no contexto da adequação ambiental e agrícola de propriedades rurais. In: BRANCALION, P.H. S.; GANDOLFI, S.; RODRIGUES, R. R. Restauração Florestal. São Paulo: Oficina de Textos, 2015. 432p.

OLIVEIRA, I. J. Chapadões Descerrados: relações entre vegetação, relevo e uso das terras em Goiás. Boletim Goiano de Geografia. (Online). Goiânia, v. 34, n. 2, p. 311-336. 2014. Disponível em: revistas.ufg.br/bgg/article/view/31734/17010. DOI 10.5216/bgg.v34i2.31734.

OLIVEIRA, L. C. S.; GUIMARAES, J. C. O.; SOUZA, I. C. S.; LIMA, C. M.; FERREIRA, W.C. Levantamento florístico e fitossociológico da regeneração natural de uma mata de galeria localizada no município de Jataí - GO. Global Science and Technology, v. 08, p. 59-77, 2015. Disponível em: https://rv.ifgoiano.edu.br/periodicos/index.php/gst/article/view/764.

Doi: http://dx.doi.org/10.14688/1984-3801/gst.v8n3p59-77 
PASA, M. C.; DAVID, M.; SÁNCHEZ, D. C. M. Copaifera langsdorffii Desf: aspectos ecológicos e silviculturais na comunidade Santa Teresa. Cuiabá, MT, Brasil. Biodiversidade, v. 11, n. 1, p.13-22, 2012. Disponível em: http://periodicoscientificos.ufmt.br/ojs/index.php/biodiversidade/article/view/702/602

PAULO, L. C. C. V.; ALMEIDA, A. A. S. Resistência à penetração em Latossolo sob floresta ripária e submetido ao pisoteio animal. Revista Ambiente \& Água, Taubaté, v. 11, p.1109-1118 (suplemento), 2016.

Disponível em:

http://www.redalyc.org/articulo.oa?id=92852596008 DOI:10.4136/ambi-agua. 1899

PAULO, A. BATALHA, F. Q.; LUTTEMBARCK, M. A. P.; RODRIGUES, R; MANHÃES, M, A. Riqueza, diversidade e composição florística em áreas de cerrado em regeneração e preservado na estação ecológica de Itirapina - SP. Ciência Florestal, Santa Maria, v.25, n.1, p.231-238, 2015. Disponível em $<$ http://www.scielo.br/scielo.php?

script=sci_arttext\&pid=S198050982015000100231\&Ing=pt\&nrm=iso > . acesso em 20 fev. 2018. Doi: http://dx.doi.org/10.1590/1980-509820152505231.

PEREIRA, I. M.; PINHEIRO, A. C.; OLIVEIRA, M. L. R.; OTONI, T. J. O.; MACHADO, E. L. M. Estrutura fitossociológica da regeneração natural de uma área de cerrado no município de Curvelo, MG. Enciclopédia Biosfera, Centro Científico Conhecer Goiânia, 2014. v.10, n.18; p.1619-1636. Disponível em: http://www.conhecer.org.br/enciclop/2014a/AGRARIAS/estrutura $\% 20$ fitossociologica.pdf.

SANTOS, G. L.; PEREIRA, M. G.; DELGADO, R. C.; TORRES, J. L. R. Natural regeneration in anthropogenic environments due to agricultural use in the Cerrado, Uberaba, MG, Brazil. Bioscience Journal, Uberlândia, v. 33, n. 1, p. 69-176, 2017. Disponível em: http://www.seer.ufu.br/index.php/biosciencejournal/article/view/35036/19765. DOI: http://dx.doi.org/10.14393/BJ-v33n1a2017-35036

SCABORA, M.H.; MALTONI, K.L.; CASSIOLATO, A.M.R. Associação micorrízica em espécies arbóreas, atividade microbiana e fertilidade do solo em áreas degradadas de cerrado. Ciência Florestal, Santa Maria , v. 21, n. 2, p. 289-301, 2011. Disponível em <http://www.scielo.br/scielo.php?script=sci_arttext\&pid=S198050982011000200289\&lng=pt\&nrm=iso>. Acesso em 20 fev. 2018. Doi: http://dx.doi.org/10.5902/198050983232.

SCOPEL, I.; SILVA, M. R. Erodibilidade no estado de Goiás. Uniciência, Anápolis, v. 8, n.1 e 2, p. 123-132, 2001. (Impresso)

SILVA, C. P. A.; LEMES, S.A. L.; MORAIS, M. F.; NETO, G. G.; CARNIELLO, M. A. Ocorrência e ecologia de Zamia boliviana (Brongn.) A.DC. em um fragmento urbano de cerrado alagável no sudoeste do estado de Mato Grosso, Brasil. Flovet, v.1, n.9, 2017. em: http://periodicoscientificos.ufmt.br/ojs/index.php/flovet/article/view/5494/3618 
SILVA, S. D.; MATEUS, R. A.; BRAZ, V. S.; PEIXOTO, J. C. A Fronteira do Gado e a Melinis Minutfora P. Beauv. (POACEAE): A História Ambiental e as Paisagens Campestres do Cerrado Goiano no Século XIX. Sustentabilidade em Debate, Brasília, v. 6, n. 2, p. 17-32, 2015. Disponível em: http://periodicos.unb.br/index.php/sust/article/view/15469. DOI: http://dx.doi.org/10.18472/SustDeb.v6n2.2015.15469

SOUZA, V.C.; LORENZI, H. Botânica sistemática: guia ilustrado para identificação das famílias de Fanerógamas nativas e exóticas no Brasil baseado em APG III. 3ed. Nova Odessa: Instituto Plantarum, 2012. 768p.

VALE, V. S.; CRESPILHO, R. F.; SCHIAVINI, I. Análise da regeneração natural em uma comunidade vegetal de cerrado no Parque Victório Siquierolli, Uberlândia-MG. Bioscience Journal, Uberlândia, v. 25, n. 1, p. 131-145, 2009. Disponível em: http://www.seer.ufu.br/index.php/biosciencejournal/article/view/6782/4476

WALLIS-DE-VRIES, M. F.; PARKINSON, A. E.; DULPHY, J. P.; SAYER, M.; DIANA, $E$. Effects of livestock breed and grazing intensity on biodiversity and production in grazing systems. 4. Effects on animal diversity. Grass and Forage Science, v. 62, n. 2, p.185-197, 2007. Disponível em: http://onlinelibrary.wiley.com/doi/10.1111/j.13652494.2007.00568.x/abstract. DOI: 10.1111/j.1365-2494.2007.00568.x 